\title{
Day Light Simulation of an Institutional Building by Using Autodesk-Ecotect
}

\author{
BR Phanikumar* and P Raju \\ Department of Civil Engineering, SRKR Engineering College, Bhimavaram, India
}

*Corresponding author: BR Phanikumar, Department of Civil Engineering, SRKR

Engineering College, Bhimavaram, India.

Received Date: October 14, 2019

Published Date: October 30, 2019

Abstract

Buildings are substantially responsible for $33 \%$ of energy consumption for air-conditioning and artificial day lighting in India. The commercial and residential buildings account for about $8 \%$ and $25 \%$ of energy consumption, respectively in India, so energy efficiency is an important criterion that needs special attention while considering sustainable buildings. Various alternate energy sources like solar, wind and geothermal energies proved to be better in creating an energy efficient built environment; along with these criteria effective utilization of daylight plays a crucial role in creating energy efficient buildings. Ecotect Day Light simulation analysis is one such case which briefs up the concept of Energy efficiency. It shows the sun path and shadow analysis of a project or a building on a particular day, time and place throughout the year (even before its construction), which would help the engineers and architects/designers to go for alternative plans for effective use of day light in construction projects, this could soon become an integral part of building and architectural design for Energy efficient buildings. The present study shows the day-light simulation and thermal performance of an institutional building for achieving the best efficiency of natural lighting and energy saving during the daytime to reach optimum daylight performance using Autodesk Ecotect.

Keywords: Daylight; Sustainability; Energy efficiency; Simulation; Sunlight; Energy

\section{Introduction}

\section{Day-light}

Day Light is the combination of all direct and indirect sunlight during the daytime. It is the light to which every individual is naturally adapted; it is the light against which all other kinds of light are measured. Historical buildings always used the source of natural light and after a brief gap, resumption in the skillful use of daylight is once again being seen as a critical element in the design and functioning of buildings of high architectural quality. The optimized design of natural day lighting for residential buildings can greatly reduce the energy consumption and improves indoor environmental quality along with physical and mental health of the residents [1]. Using sunlight as a major source of light, a reduction in power consumption can be achieved to some extent. A power flux of $63 \mathrm{MW}$ is released by the sun which is equivalent to 6000 million lumens/m2of its surface area. Out of this nearly 134 kilolux reaches the earth's outer atmosphere which absorbs about $20 \%$ of this light and reflects another $25 \%$ back into outer space. A fraction of the remaining $55 \%$ reaches the ground directly, as sunlight, the rest is first diffused by the atmosphere (skylight) - these two together make up daylight [2]. Day light in LEED refers to connect building occupants with the outdoors, reinforce circadian rhythms, and reduce the use of electrical lighting by introducing daylight into the architectural space. Architects should incorporate criteria for LEED/GRIHA/IGBC (Green building rating systems) daylight credit into building design process while considering heat gain and loss factors, glare control, visual quality and variations in daylight availability [3].

\section{Day lsight simulation}

Daylight simulation is a technique to predict the amount of sunlight entering the room in a pre -planning stage itself. In certain cases, it may even suggest a change in the design of structure. Simulated daylight measurement, which estimates daylight quality levels became more accurate because of using global metrics established by various day lighting professionals [3]. Daylight factor is one of the metrics used to assess day lighting performance. It is defined as the ratio between the internal illuminance in a building at a certain point and the external horizontal illuminance [4]. Many designers, while finding the day light simulations useful as a learning technique, and for developing parameters such as room configuration, door and window sizes, and surface reflection studies, are unwilling to depend on it when making final decisions 
on the visual effectiveness and aesthetic quality of a particular design proposal [2]. In order to get the real benefits of simulation process, the simulation results should be used as the main tool for the design, rather than using it at the end of design process. The simulation process cannot be evaluated by using only one type of software, it is a complex flow of work which initiates from making a 3D dynamic model that can be modified without recreating the 3D model every time, followed by connecting it with validated simulation tool to ensure the correct analysis results. These results are evaluated to give us a numerical and visual feedback after being processed by simulation optimization which automatically adjusts different variables in order to get better simulation results which eventually derives an optimized solution [5]. Energy efficiency and indoor environment have become increasingly important in building design. Building developers, engineers and designers are straining to produce buildings with lower energy consumption and higher energy efficiency. The amount of energy a building consumes for its operation and maintenance is almost equivalent to amount of its carbon emissions. This attention to energy performance has led to growing awareness that, in order to achieve low energy buildings with satisfactory indoor climate, the designer must be aware of the consequences of critical design decisions in the initial stages of design process [6]. Maintaining the comfort level of a building through artificial heating or cooling accounts for a major portion of the total energy consumption. Artificial lighting not only consumes electrical energy but also adds to the cooling loads as a result of the heat generated by various power consuming and lighting appliances. The most cost-effective reduction in energy consumption occurs during the design process, by implementing design strategies such as orientation of the building, massing of the built structure, using energy efficient building materials, photovoltaic systems, natural day light, and shading devices, designers can significantly reduce thermal loads of a building Even though daylight is recognized as an effective means to reduce the artificial lighting requirements of buildings, daylight is still an underexploited natural resource [7].

\section{Autodesk ecotect}

Autodesk Ecotect is a sustainable design analysis software which is a comprehensive concept to detail sustainable building design tool. It offers a wide range of simulation and building energy analysis functionality that can improve performance of both existing buildings and new building designs. It allows designers to simulate and analyze the building performance from the earliest stages of conceptual design. It combines the analysis functions with an interactive display that gives analytical results directly within the context of the building model. It has a very user-friendly interface that allows building and creating 3D models with ease. The survey results conducted by [8] showed that $64 \%$ of the architects/ engineers, used Autodesk Ecotectas building performance simulation tool. The study also showed that Ecotect was mostly used during conceptual phase and design development phase of the project. It gives relevant information about various studies such as day light analysis, shadow analysis, thermal properties, shadows and reflections, shading devices, and solar radiation etc. [9].

\section{Methodology}

The main objective of this study is to know how Autodesk Ecotect Daylight simulation analysis improves the energy efficiency and performance of an institutional building at Vishnu Institute of Technology, Bhimavaram, depending on its direction, orientation, shadow, material reflection etc., a 3D model of the two blocks (Block-1 (B-1) \& Block-2 (B-2)shown in Figure 1 was created in the AutoCAD software and then exported into Ecotect. Figure 2 shows the daily sun-path diagram on16thMarch, 2019. Figure 3 shows the annual sun path analysis over B-1 \& B-2. Building information such as site location, orientation, altitude, wind analysis and terrain were input into the model. B-1 have a light well which provides necessary day light to the classrooms throughout the day, whereas B-2 doesn't have it. The distance between the two blocks is 15 feets. The offset of buildings is 1650 (Figures 1-3).

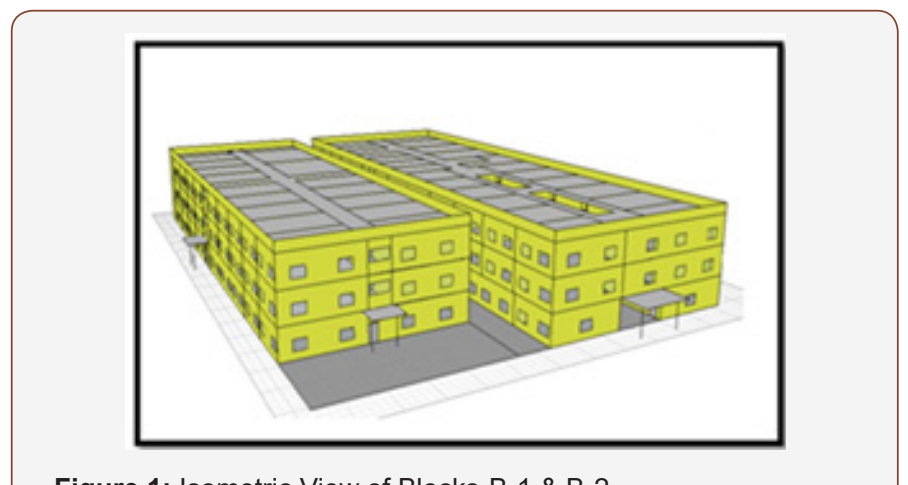

Figure 1: Isometric View of Blocks-B-1 \& B-2.

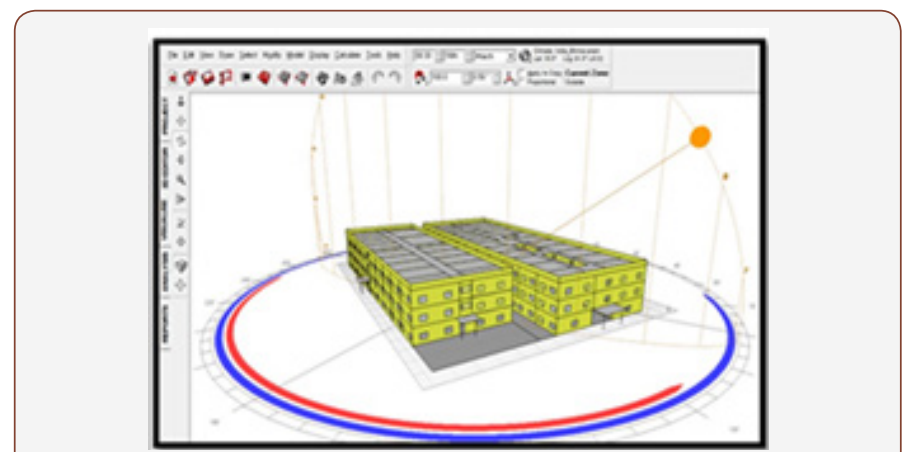

Figure 2: Daily Sun path over Blocks- B-1 \& B-2.

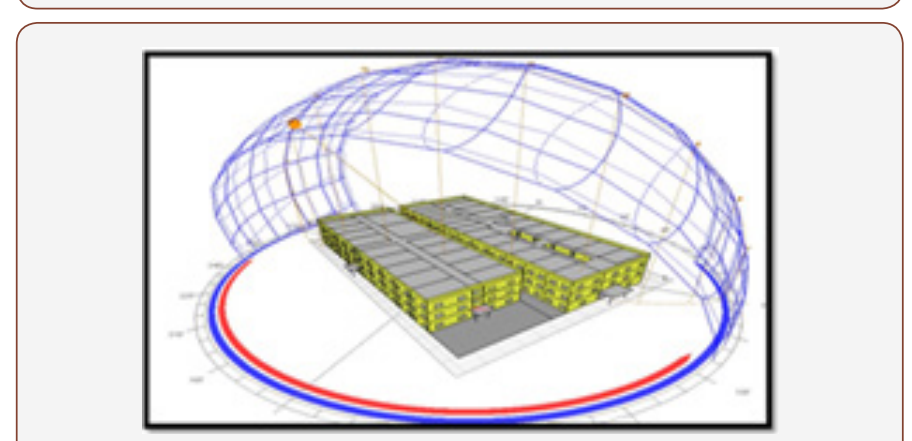

Figure 3: Annual Sun path over Blocks- B-1 \& B-2.

The Sky Luminance distribution model in Ecotect has two possible values, overcast sky condition and Uniform sky condition. The illuminance levels were calculated for both B-1 \& B-2, under the skylights, in the classrooms and corridors. The increased 
accuracy mode was chosen as the more effective way to calculate the illuminance levels as it considers both the transparency and refractive index of window glazing and the actual surface reflectance of external obstructions. An average value of 0.85 was used for window cleanliness (Figures 4,5).

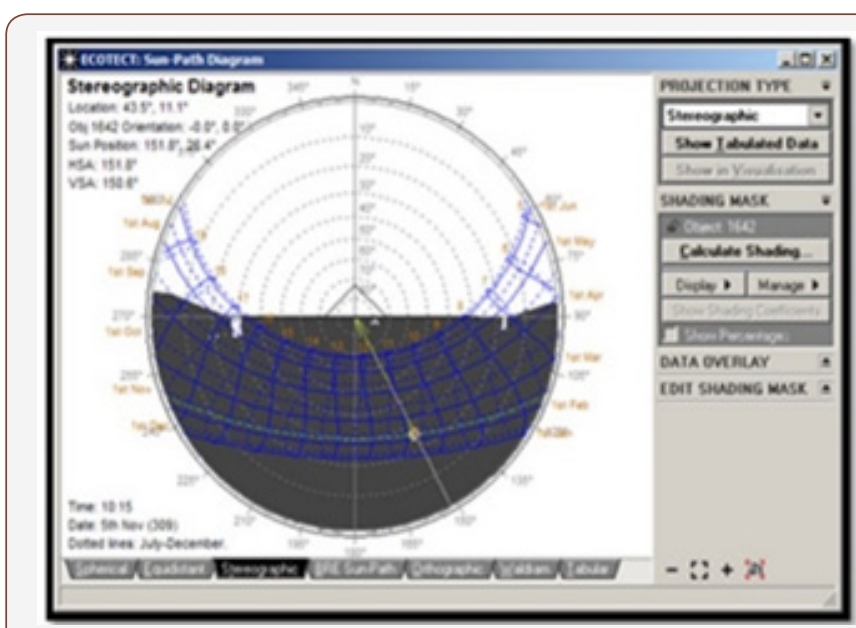

Figure 4: Sun path (Stereographic projection).

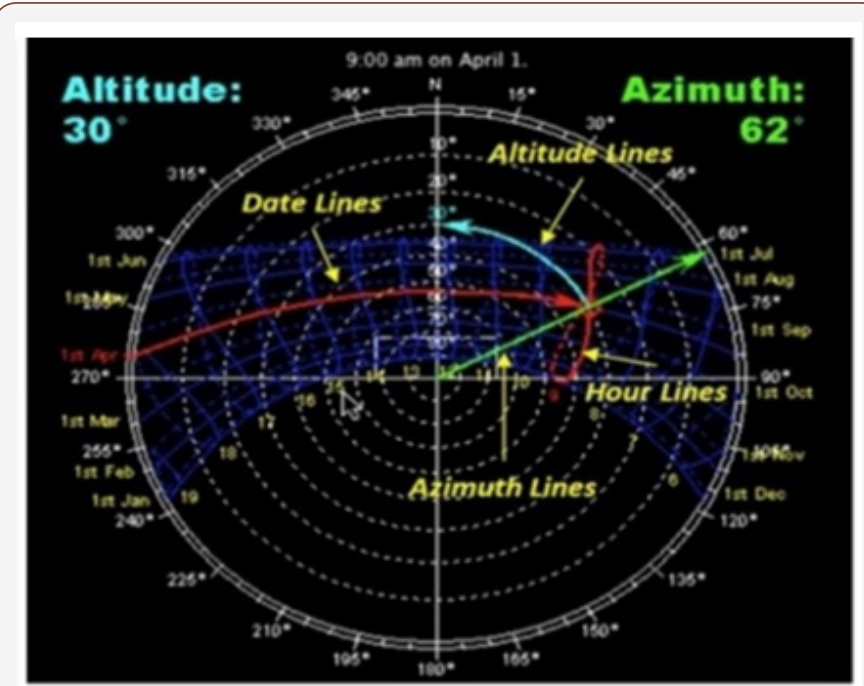

Figure 5: Altitude, Azimuth, Date and Hour Lines.

Solar analysis and Sun path analysis gives us a more advanced algorithm which is fully integrated with Ecotect. the distribution of solar radiation can be visualized and quantified for any date and time and directly display the results on the 3D model. The interactive sun path tool within Ecotect allows the sun path to be visualized to study the impact of natural light and shadows on the exteriors and interiors of the project at any location. This tool is fully integrated with Ecotect and can be used to create solar studies for any moment in time, in addition to any specified time range. The integrated Energy Analysis has been enhanced in Ecotect to support more detailed building elements performed using Green Building Studio, and to calculate total energy use and cost on an annual, monthly, daily, and hourly basis, using a global database of weather information.

\section{Result and Discussion}

Shadow analysis for existing geometry: Shadow analysis for Blocks B-1 \& B-2 for every hour between the time interval 8:30AM to 4:30PMfrom March to April 2019, the sun path and shadow analysis for each block is taken for a day i.e., on 1st April 2019, to show the detailed day lighting analysis and performance of the building hourly (Figures 6-8).

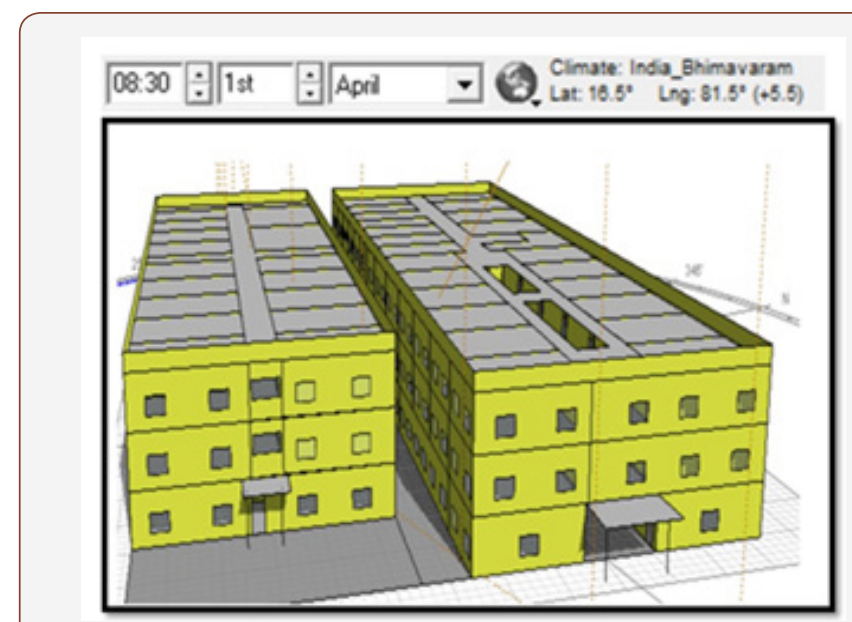

Figure 6: Shadow Analysis on B-1 \& B-2 at 08:30 AM.

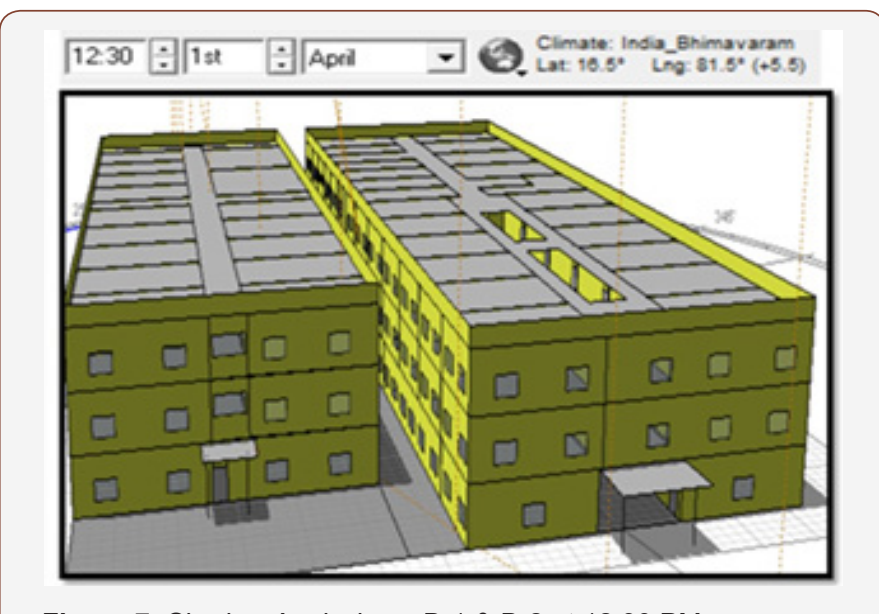

Figure 7: Shadow Analysis on B-1 \& B-2 at 12:30 PM.

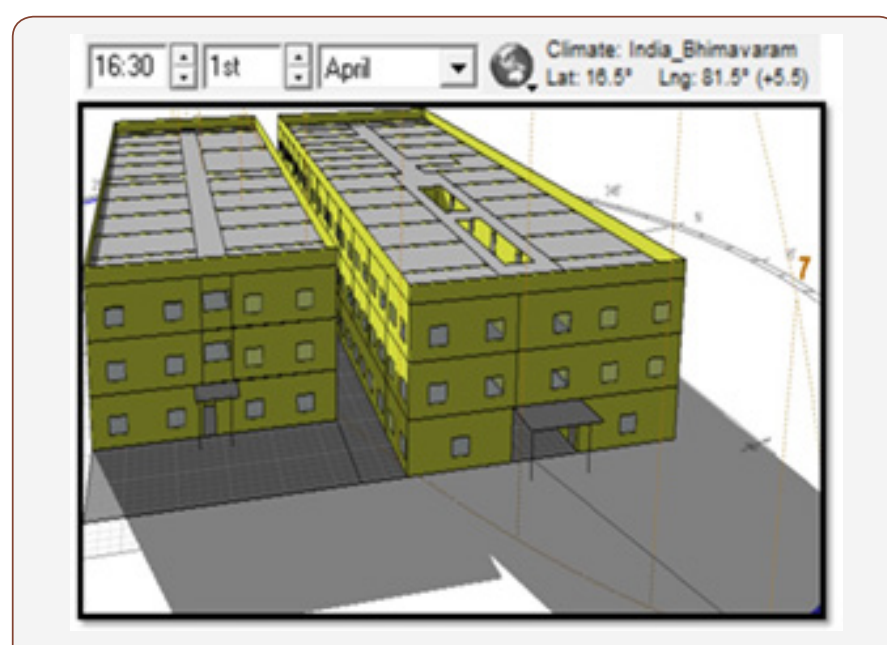

Figure 8: Shadow Analysis on B-1 \& B-2 at 04:30 PM.

Distribution of solar rays for existing geometry: To analyze the distribution of solar rays inside the rooms of the blocks, a classroom in Block 1 is selected as shown in fig 6 and is analyzed in ECOTECT starting from 8:30AM to 5:30PM on 1st April. The results so obtained are shown below (Figures 9-12). 


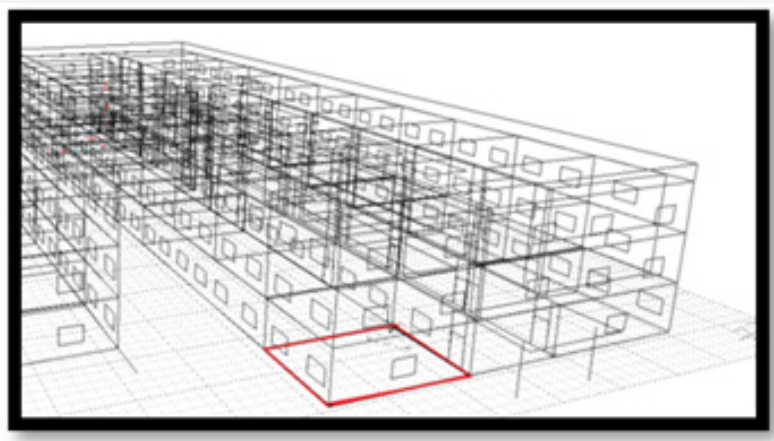

Figure 9: Room in block I selected for solar ray distribution analysis.

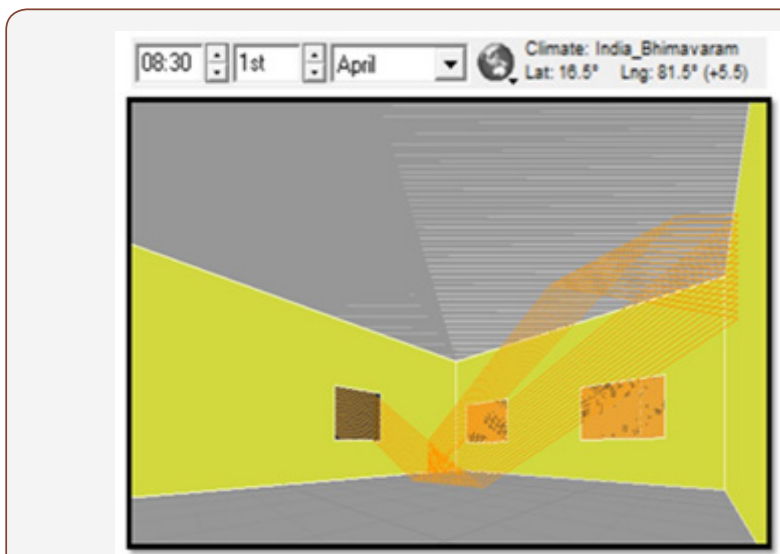

Figure 10: Optimum Moisture Content vs Plastic Limit.

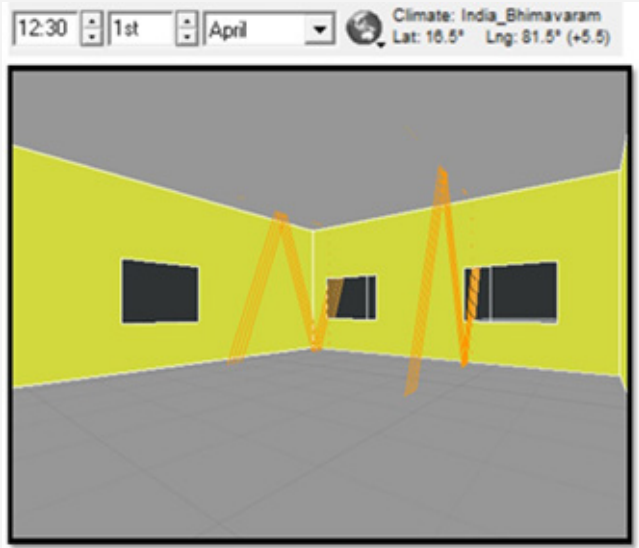

Figure 11: Solar Analysis at 12:30 PM

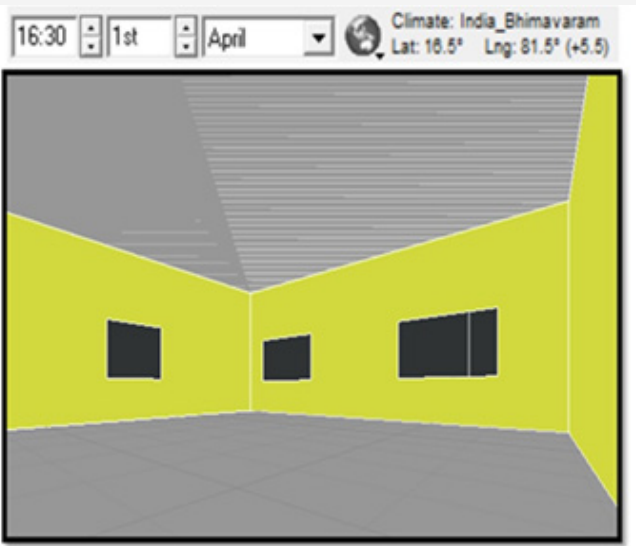

Figure 12: Solar Analysis at 04:30 PM.
The shadow analysis and solar analysis clearly states that the distribution and reflection of solar rays decreases with the time and the effect of shadows on the selected room can be clearly seen at 4:30PM in Figure 12, where there is no solar rays or its reflection from the openings and the surface that are passing through the geometry of the room. In order to obtain greater efficiency and penetration of solar rays and minimize the effect of shadows on both building blocks, the existing geometry is recreated, and the entire analysis has been done to evaluate the same process. Shadow analysis of recreated geometry: The geometry of the existing buildings has been recreated by taking many trails i.e., the existing 1650 North offset is changed to 1700 North and the distance between the two blocks is increased from 15 feet's to 30 feet's and the analysis has been carried out to clearly state the difference between the existing geometry and recreated geometry, and this recreated geometry gave the best results (Figure 13).

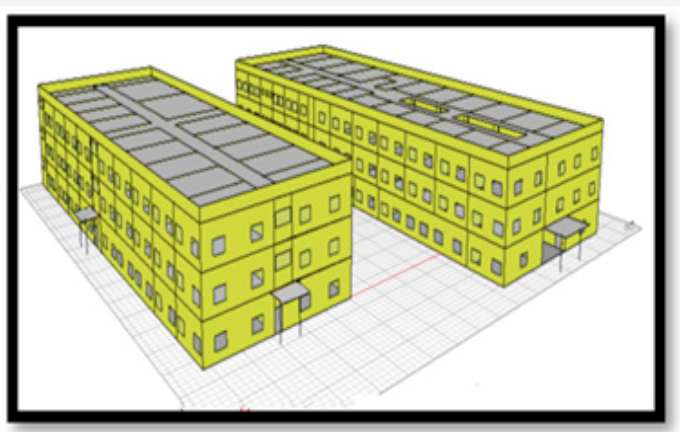

Figure 13: Recreated geometry of existing blocks.

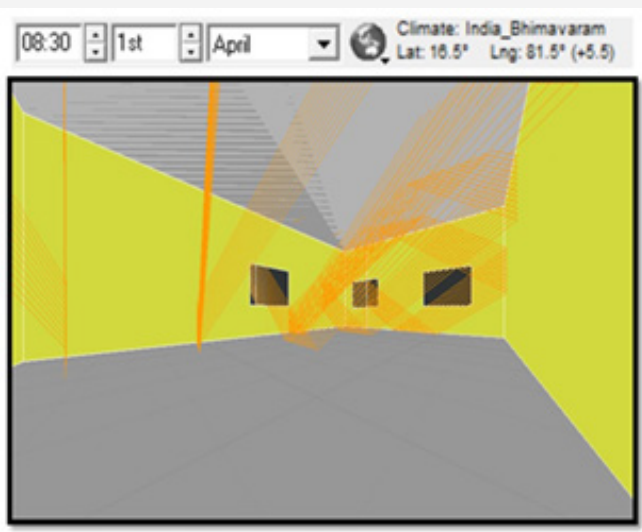

Figure 14: Solar Analysis at 08:30 AM.

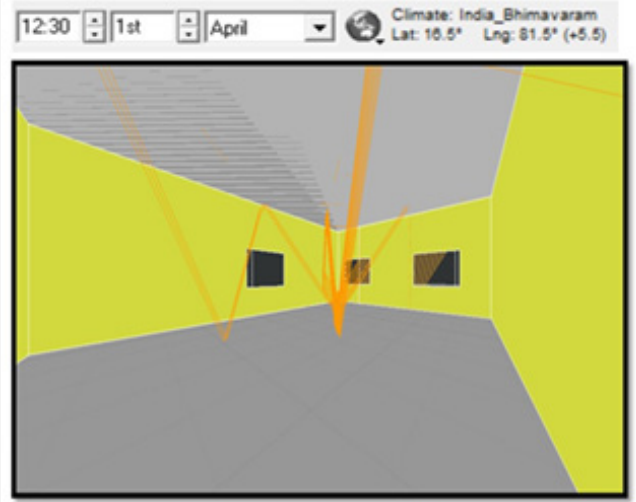

Figure 15: Solar Analysis at 12:30 PM. 
The shadow analysis and solar analysis of the recreated geometry is carried out in similar manner to that of existing geometry. The simulations so obtained are shown below (Figures 14-16).

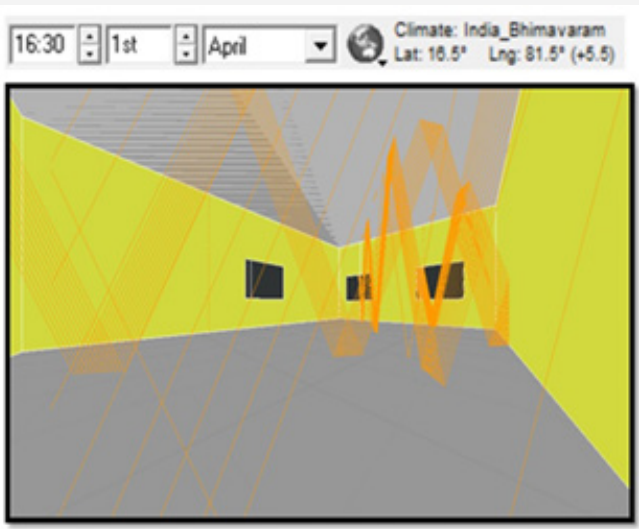

Figure 16: Solar Analysis at 04:30 PM
The difference in the shadow analysis and the solar analysis gave a clear view that the architectural design has so much to do with a project in the planning stages, in the present study, the analysis is carried out on an existing building where slight modifications can be done to increase the energy performance of the entire building, whereas for a project under planning stage, major changes can be made to obtain greater energy efficiency and optimization. In addition to shadow analysis and solar analysis on B-1 \& B-2 a Light analysis is analyzed to show the ingress of light intensity in all the classrooms and corridors. Complete light analysis of B-1 \& B-2: The complete sun path of a day has been traced out using Ecotect for the existing geometry and the recreated geometry of B-1 \& B-2. The results showed a great variation in the illuminance levels of B-1 \& B-2 from the existing geometry to recreated geometry. Fig 17 and 18 shows the variation of illuminance levels of B-1 and Figure 19 and Figure 20 shows the variation of illuminance levels of B-2 (Figures 17-20).

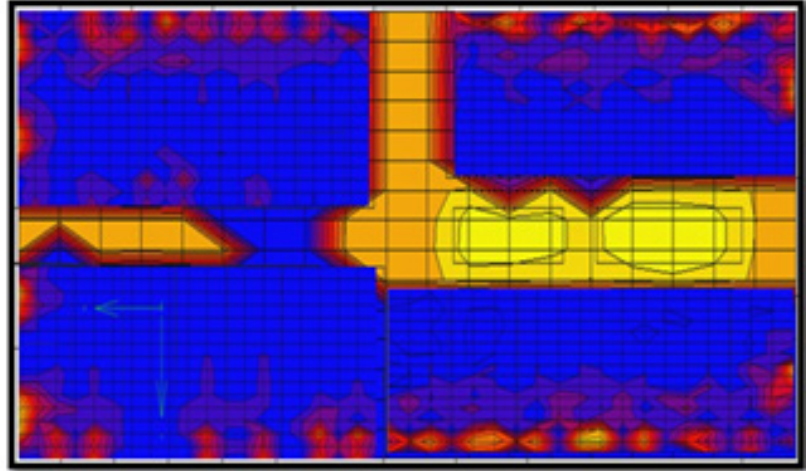

Figure 17: Light Analysis for B-1 Existing Geometry.

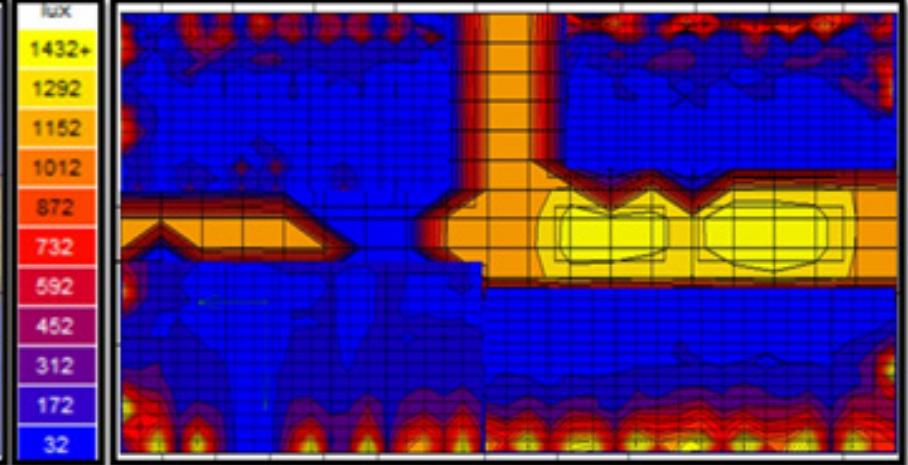

Figure 18: Light Analysis for B-1 Recreated Geometry.

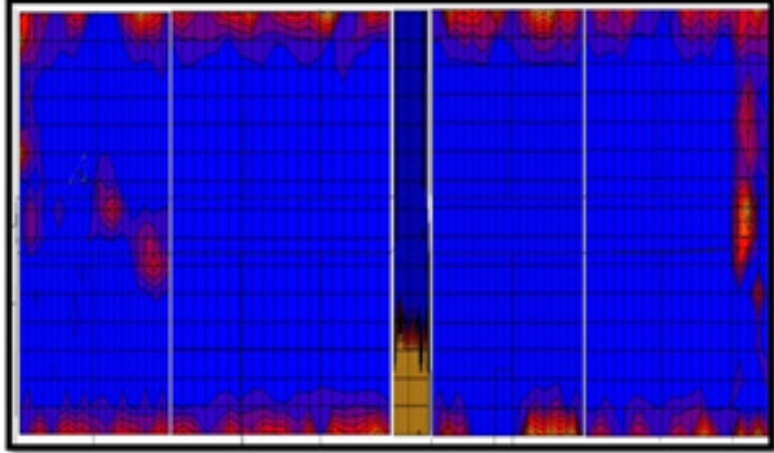

Figure 19: Light Analysis for B-2 Existing Geometry.

So, these results suggest that, effective utilization of day lighting can be achieved by the geometrical shape, orientation, material reflection and by minimizing the shadows on the structure due to other structures in the vicinity, thereby increasing the energy efficiency and creating a better living environment to the occupants.

\section{Conclusion}

1. It has been clearly evident from the complete analysis that the Day light simulation has very much to do with the geometry and orientation of the building.
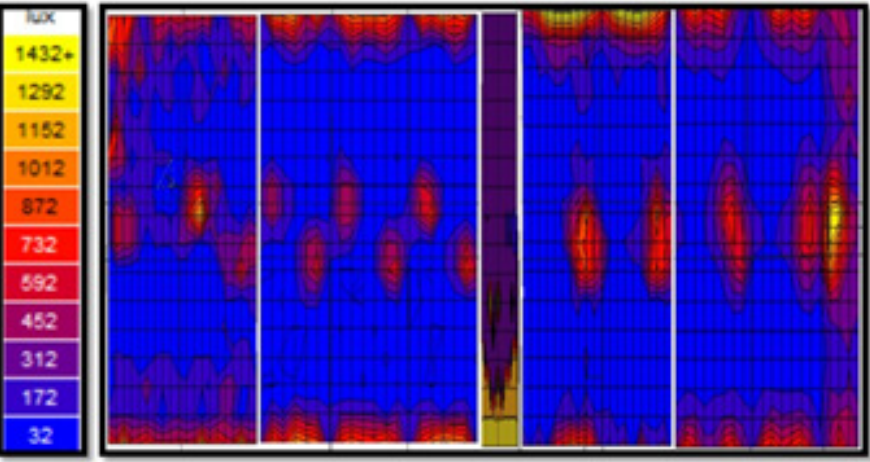

Figure 20: Light Analysis for B-2 Recreated Geometry.

2. Ecotect is different from other analysis tools, that it targets the earliest stages of building design, a time when simple decisions may have umpteen effects on the final result of a project.

3. The analysis proved to be worthy, easy and highly economical in planning stages of construction projects. It can also be used for existing buildings where slighter modification can be made. 
4. This analysis functions with an interactive display that presents analytical results directly within the context of the building model.

5. This software can easily detect the complete sun path and shadow analysis of each and every room of a building. It has been proved to be worthy, when considering the energy efficiency of a building.

6. In 21st century many organizations (both government and non-government) has been giving importance for Energy efficiency. So, this simulation software's could change the scenario of Energy efficient buildings.

\section{Acknowledgement}

None.

\section{Conflict of Interest}

No conflict of interest.

\section{References}

1. Meng Z, Yizhao D, Fenghuan H, Guangmeng B (2019) Simulation analysis of natural lighting of residential buildings in Xian, China. Science of The Total Environment 690: 197-208.
2. Energy Research Group (1994) Daylighting in Buildings. The European Commission Directorate-General for Energy (DGXVII).

3. Shehata S, Elshimy H (2018) Energy Saving and Natural Day lighting Simulation for an Administrative Building in Samalut City. Energy and Sustainable Development, Egypt.

4. Reinhart C, Mardaljevic J, Rogers Z (2006) Dynamic Daylight Performance Metrics for Sustainable Building. Leukos 3(1): 7-31.

5. Wagdy Mohamed IA (2013) New Parametric workflow based on validated day-lighting simulation. Building Simulation Cairo 2013 Towards Sustainable \& Green Life, Italy.

6. Krygiel E, Nies B (2008) Green BIM: Successful Sustainable Design with Building Information Modeling. Wiley Publishing, Inc.

7. Nabil A, Mardaljevic J (2005) Useful daylight illuminance: A new paradigm for assessing daylight in buildings Lighting Research \& Technology 37: 41-57.

8. Attia S, Beltran L, De Herde A, Hensen J (2009) Architect Friendly: A comparison of ten different building performance tools. Building Simulation Eleventh International IBPSA Conference, USA.

9. Vangimalla PR, Olbina S, Issa R, Hinze J (2011) Validation of Autodesk Ecotect $^{\mathrm{TM}}$ accuracy for thermal and daylighting simulations. Winter Simulation Conference, Florida, USA, pp.3383-3394. 